\title{
Knowledge and self-care in diabetes mellitus and their correlations with sociodemographic, clinical and treatment variables
}

\author{
Moraes NM${ }^{1}$, Souza GFP ${ }^{1}$, Brito FI ${ }^{1}$, Antonio Júnior ME ${ }^{1}$, Cipriano AE ${ }^{1}$, Costa NSV $^{2,3}$, Rezende TM ${ }^{1}$, Silva Júnior AJ ${ }^{1}$ and Gomes LC ${ }^{1 *}$ \\ ${ }^{1}$ University Center of the Guaxupé Educational Foundation (UNIFEG), Guaxupé, Minas Gerais, Brazil \\ ${ }^{2}$ Family and Community Physician in Primary Health Care in Guaxupé, Minas Gerais, Brazil \\ ${ }^{3}$ UNASUS-UERJ, Rio de Janeiro, RJ, Brazil
}

\begin{abstract}
Objective: To assess knowledge and self-care in diabetes mellitus, and to verify their correlations with sociodemographic, clinical and treatment variables.

Methods: Cross-sectional and correlational study, involving 33 adults with type 2 diabetes mellitus in a city in the interior of Minas Gerais, Brazil. For data collection, instruments validated for Brazilian culture were used, applied through individual interviews.

Results: Satisfactory knowledge about diabetes was obtained and self-care dimensions with the best performance were "general food" and "physical activity". There were correlations between knowledge and schooling time, income and insulin treatment, "general diet" with income, "medication" and "blood glucose monitoring" with insulin treatment, and monitoring was also correlated with the time of diagnosis.

Conclusion: Identifying the interfering variables in the self-care process is essential for the success of educational actions in controlling the disease and promoting quality of life.
\end{abstract}

\section{Introduction}

Among chronic non-communicable diseases, diabetes mellitus (DM) is characterized as a substantially challenging condition, whether due to the need for lifestyle changes or the complexity of drug therapy [1], which may include different drugs oral with or without the combination of insulins [2].

In this perspective, knowledge about DM and its management becomes a fundamental requirement for understanding and engaging the person in their self-care, as well as for making daily decisions about the demands related to the disease and treatment [3]. Although having appropriate knowledge of the disease does not mean the acquisition of new habits, it is important to know people's understanding of their own health status in order to plan any care intervention, since people's knowledge and beliefs can influence the self-care process [4].

The concept of self-care is also particularly relevant for the management of long-term illnesses [5] since, from the perspective of empowerment, the person affected by a disease of this nature becomes a "specialist" in everyday management their condition [3]. "It refers to the person's skills and the performance of health promotion and maintenance activities, including specific activities for acute and chronic situations" [5]. These are initiatives taken by people that include preventive behaviors, adherence to treatment and other health interventions, such as, for example, interaction with social support networks and health education [3].
Recognizing that health education is of special importance for diabetic individuals, a group of DM educators in the United States of America identified, in 1997, seven self-care behaviors (eating healthily, staying active, monitoring oneself, taking medication, solving problems, facing positively and reducing risks), in order to provide a framework for the development of educational interventions centred on people's goals, and not on the content planned by professionals [6].

A literature review study on the education of people with chronic diseases indicates that the first stage of an educational program is evaluative. This includes an assessment of cognition, prior knowledge and possible misconceptions, as well as attitudes, motivation, skills and learning style. From this assessment, it is possible to identify people's resources, barriers and educational needs [7]. Educational interventions for people with DM tend to be more effective when knowledge about the disease is assessed [3]. The literature also suggests that the recognition of demographic, social and clinical factors, which can be barriers or facilitators of self-care, is essential for the development of effective interventions [8].

${ }^{*}$ Correspondence to: Lilian Cristiane Gomes, UNIFEG - Avenida Dona Floriana, 463, Centro. Guaxupé, Minas Gerais, Brazil, E-mail: liliancristianegomes@yahoo.com.br

Key words: diabetes mellitus, knowledge, self-care, nursing care

Received: March 04, 2020; Accepted: March 18, 2020; Published: March 24 2020 
Thus, the present study aimed to assess knowledge and self-care in $\mathrm{DM}$, and to verify its correlations with sociodemographic, clinical and treatment variables.

\section{Materials and methods}

This is a cross-sectional and correlational study, with a quantitative approach, developed at the Center for Health Studies and Physical Education (CESEF) of the University Center of the Guaxupé Educational Foundation (UNIFEG), from August 2017 to October 2018.

This study constitutes the first phase of the matrix project entitled "Evaluation of an educational program for people with type 2 diabetes mellitus, with a focus on the practice of physical activities and foot care", approved by the Research Ethics Committee of UNIFEG, Opinion No. 2,029,352, of May 3, 2017. This first phase refers to the first collection of variables of interest, which took place prior to the interventions of the matrix project.

The base population consisted of adults with a medical diagnosis of type 2 DM (DM2), regardless of the duration of the disease, who were not hospitalized and under outpatient follow-up. The invitation to the study was carried out in public health services and by the local media. For sample selection, the following inclusion / exclusion criteria were considered:

- Inclusion criteria: people of both sexes, at least 40 years old, sedentary or not very active, without complications at an advanced stage, whose drug treatment included the use of oral antidiabetic drugs (OADs) and / or insulin, and who were able to maintain dialogue.

- Exclusion criteria: people with DM2 who had at least one of the following conditions were excluded: undergoing hemodialysis, amaurosis, presence of sequelae of stroke/ heart failure, previous amputations at any level of the lower limb, injury or ulcer process active in lower limbs, presence of any other disabling complications; use of a wheelchair and/or stretcher; inability to verbal communication; and participants in a physical training program at another institution.

Thus, the sample consisted of 33 adults with DM2 who met the inclusion criteria and voluntarily attended the study site. After being instructed on the objectives and procedures of the study, data were collected in a private room, in the form of individual interviews, with an average time of 30 minutes.

Sociodemographic, clinical and treatment data were obtained using a structured instrument, based on the literature and the professional experience of the researchers [9].

For the evaluation of knowledge about the disease, the revised Brazilian version of the Diabetes Mellitus Knowledge (DKN-A) instrument was used $[10,11]$. It has 15 multiple choice items on different aspects related to the general knowledge of DM. It presents five broad categories: a) basic physiology, including the action of insulin, b) hypoglycemia, c) food groups and their substitutions, d) management of DM in the event of some other disease, e) general principles of disease care.

Self-care was assessed by the Diabetes Self-Care Activities Questionnaire (DSCAQ) [12], which is a scale composed of 15 items in six dimensions (general food, specific food, physical activity, blood glucose monitoring, foot care and medication) and three other items related to smoking. Each dimension is evaluated by means of the averages of the items that compose them, in days per week, as recommended in the validation study of this instrument for Brazilian culture [12].

The data collected was double entered in the MS-Excel application and then processed electronically for validation. Subsequently, the data sheet was exported to the Statistical Package for Social Science (SPSS) software, version 17.0. The numerical variables were subjected to the Komolgorow-Smirnov and Levene tests to verify, respectively, the normal distribution and homogeneity of the variances. Descriptive statistics were used to characterize the sample and, for comparisons of means between two independent groups, the Mann-Whitney test was used, as well as the Spearman correlation coefficient, since the normal distribution was not evident. The results were expressed as mean and standard deviation, with a significance level (p) of less than 0.05 .

\section{Results}

\section{Sociodemographic, clinical and treatment characterization of the sample}

It is noteworthy that the sample studied consisted of $78.8 \%$ of people of the female sex; mean age of 60.2 years (standard deviation - $\mathrm{SD}=11.5)$; average schooling time of 6.4 years $(\mathrm{SD}=5.2)$; average diagnosis time of 8.5 years $(\mathrm{SD}=7.8)$; use of $\mathrm{OADs}$ as a prescription drug treatment $(78.8 \%)$; absence of previous participation in diabetes guidance groups (100\%), and practice of some type of physical activity, even if sporadically (58\%) (Table 1$)$.

\section{Knowledge about the disease and self-care activities}

In the knowledge assessment, an average score of 9.2 points $(\mathrm{SD}=2.8)$ was obtained and, regarding self-care activities with $\mathrm{DM}$, the highest averages were for the dimensions "specific food" and "physical activity", and the lowest mean, for the "blood glucose monitoring" dimension (Table 2).

Tables 3 and 4 show the correlations between knowledge and selfcare with sociodemographic and clinical / treatment variables.

Knowledge correlated directly and statistically significantly with education $(\mathrm{p}=0.000)$ and with monthly family income $(\mathrm{p}=0.020)$, suggesting that the higher the education and income, the greater the knowledge about the disease. Income also showed a significant correlation with the performance of the dimension "general food" ( $\mathrm{p}=0.040$ ), which suggests that the higher the income, the greater the possibility of following a balanced general diet. The time of diagnosis was correlated with the dimension "blood glucose monitoring" $(\mathrm{p}=0.006)$, which denotes that the performance of this dimension is more frequent among people with longer disease progression (Table 3 ).

As for drug treatment, insulin users showed greater knowledge about DM than those who use only OADs $(\mathrm{p}=0.018)$. The average number of days per week for "blood glucose monitoring" and "medication" were also higher among insulin users ( $\mathrm{p}=0.003$ and $\mathrm{p}=0.002$, respectively) (Table 4).

\section{Discussion}

The studied sample is characterized by the predominance of females, in the sixth decade of life, with low education and income, average time of diagnosis less than 10 years, use of OADs as prescribed drug treatment, and absence of previous participation in groups of guidance on the disease. In general, these results are similar to those of other studies developed among Brazilian population samples of people with DM [13-17]. 
Table 1. Sociodemographic, clinical and treatment characterization of the studied sample. Guaxupé, Minas Gerais, Brazil, 2018

\begin{tabular}{|c|c|c|}
\hline Variables $(\mathbf{N}=\mathbf{3 3})$ & n (\%) & Average (SD*) \\
\hline \multicolumn{3}{|l|}{ Sex } \\
\hline Female & $26(78.8)$ & \\
\hline Male & $7(21.2)$ & \\
\hline Age & & $60.2(11.5)$ \\
\hline Monthly family income (in Reais) $)^{\ddagger}$ & & $2092.77(1669.59)$ \\
\hline Schooling time (in years) & & $6.4(5.2)$ \\
\hline \multicolumn{3}{|l|}{ Marital status } \\
\hline Single & $3(9.1)$ & \\
\hline Married & $20(60.6)$ & \\
\hline Separated / divorced & $4(12.1)$ & \\
\hline Widower & $6(18.2)$ & \\
\hline \multicolumn{3}{|l|}{ Ocupation } \\
\hline Active in the labor market & $6(18.2)$ & \\
\hline Retired with remunerated activity & $2(6.1)$ & \\
\hline Retired/pensioner & $18(54.5)$ & \\
\hline Work at home, no pay & $4(12.1)$ & \\
\hline Unemployed / away from work & $3(9.1)$ & \\
\hline Time of diagnosis (in years) & & $8.5(7.8)$ \\
\hline \multicolumn{3}{|l|}{ Drug treatment of diabetes } \\
\hline Only oral antidiabetic drugs (OADs) & $26(78.8)$ & \\
\hline Only insulin & $1(3)$ & \\
\hline Associations (OADs + insulin) & $6(18.2)$ & \\
\hline OADs usage time (in years) & $5.6(5.5)$ & \\
\hline Number of pills per day & $2.7(1.7)$ & \\
\hline Insulin usage time (in years) & $8(7.5)$ & \\
\hline Number of injections per day & $2.2(0.4)$ & \\
\hline \multicolumn{3}{|c|}{ Prior participation in a diabetes orientation group } \\
\hline No & $33(100)$ & \\
\hline \multicolumn{3}{|c|}{ Attendance to scheduled returns by the health unit } \\
\hline Yes & $30(90.9)$ & \\
\hline No & $3(9.1)$ & \\
\hline \multicolumn{3}{|c|}{ Practicing some type of physical activity, even if sporadically } \\
\hline Yes & $19(58)$ & \\
\hline No & $14(42)$ & \\
\hline
\end{tabular}

* SD: standard deviation

${ }^{\ddagger}$ In 2018, USD \$ 1 was equivalent to R \$ 3.65; so R \$ 2092.77 was equivalent to USD \$ 573.37

Source: survey data, 2018

Table 2. Knowledge and self-care with diabetes in the studied sample. Guaxupé, Minas Gerais, Brazil, 2018

\begin{tabular}{|c|c|c|}
\hline Variables (N=33) & Average (SD*) & Range obtained \\
\hline Diabetes Knowledge (DKN-A) & $9.2(2.8)$ & $2.0-14.5$ \\
\hline Diabetes Self-Care (DSCAQ) & & $0-6.5$ \\
\hline General food & $2.1(1.8)$ & $1.3-7.0$ \\
\hline Specific food & $4.7(1.3)$ & $1.3-7.0$ \\
\hline Physical activity & $4.7(1.3)$ & $0-7$ \\
\hline Blood glucose monitoring & $1.6(2.5)$ & $0-6$ \\
\hline Foot care & $3.3(1.8)$ & 0 \\
\hline
\end{tabular}

*SD: standard deviation

Source: survey data, 2018 
Table 3. Correlations between the means of knowledge and self-care with diabetes, with the sociodemographic and clinical / treatment variables, of a numerical nature, in the studied sample. Guaxupé, Minas Gerais, Brazil, 2018

\begin{tabular}{|c|c|c|c|c|c|c|c|c|c|c|c|c|c|c|}
\hline \multirow{2}{*}{$\begin{array}{c}\text { Variables } \\
(\mathbf{N}=33)\end{array}$} & \multicolumn{2}{|c|}{ Knowledge } & \multicolumn{2}{|c|}{ General food } & \multicolumn{2}{|c|}{ Specific food } & \multicolumn{2}{|c|}{ Physical activity } & \multicolumn{2}{|c|}{$\begin{array}{c}\text { Blood glucose } \\
\text { monitoring }\end{array}$} & \multicolumn{2}{|c|}{ Foot care } & \multicolumn{2}{|c|}{ Medication } \\
\hline & $\operatorname{CCS}^{\Phi}$ & $p$ & $\mathbf{C C S}^{\Phi}$ & $p$ & $\mathbf{C C S}^{\Phi}$ & $p$ & $\mathbf{C C S}^{\Phi}$ & $p$ & $\operatorname{CCS}^{\Phi}$ & $p$ & $\mathbf{C C S}^{\Phi}$ & $p$ & $\mathrm{CCS}^{\Phi}$ & $p$ \\
\hline Age & -0.199 & 0.275 & 0.235 & 0.195 & 0.005 & 0.980 & 0.005 & 0.980 & 0.133 & 0.467 & 0.128 & 0.484 & -0.335 & 0.061 \\
\hline Schooling time & 0.605 & $0.000 *$ & -0.103 & 0.576 & 0.273 & 0.130 & 0.273 & 0.130 & 0.278 & 0.123 & 0.015 & 0.933 & 0.147 & 0.422 \\
\hline $\begin{array}{l}\text { Monthly family } \\
\text { income }\end{array}$ & 0.416 & $0.020 *$ & 0.371 & $0.040 *$ & 0.195 & 0.293 & 0.195 & 0.293 & -0.048 & 0.798 & -0.085 & 0.649 & -0.090 & 0.631 \\
\hline $\begin{array}{c}\text { Time of } \\
\text { diagnosis }\end{array}$ & 0.242 & 0.182 & 0.085 & 0.644 & 0.107 & 0.559 & 0.107 & 0.559 & 0.474 & $0.006 *$ & 0.310 & 0.084 & 0.108 & 0.557 \\
\hline
\end{tabular}

${ }^{\Phi}$ Spearman's correlation coefficient

$*$ Statistical significance $(\mathrm{p}<0.05)$

Source: survey data, 2018

Table 4. Comparisons of the means of knowledge and self-care with diabetes, with the sociodemographic and clinical / treatment variables, of a nominal nature, in the studied sample. Guaxupé, Minas Gerais, Brazil, 2018

\begin{tabular}{|c|c|c|c|c|c|c|c|c|c|c|c|c|c|c|}
\hline \multirow{2}{*}{$\begin{array}{c}\begin{array}{c}\text { Variables } \\
(\mathbf{N}=33)\end{array} \\
\mathrm{Sex}^{\dagger}\end{array}$} & \multicolumn{2}{|c|}{ Knowledge } & \multicolumn{2}{|c|}{ General food } & \multicolumn{2}{|c|}{ Specific food } & \multicolumn{2}{|c|}{ Physical activity } & \multicolumn{2}{|c|}{$\begin{array}{c}\text { Blood glucose } \\
\text { monitoring }\end{array}$} & \multicolumn{2}{|c|}{ Foot care } & \multicolumn{2}{|c|}{ Medication } \\
\hline & $\begin{array}{c}\text { Average } \\
\left(\text { SD }^{*}\right)\end{array}$ & $p$ & $\begin{array}{c}\text { Average } \\
\left(\text { SD }^{\#}\right)\end{array}$ & $p$ & $\begin{array}{c}\text { Average } \\
\left(\text { SD }^{*}\right)\end{array}$ & $p$ & $\begin{array}{c}\text { Average } \\
\left(\text { SD }^{*}\right)\end{array}$ & $p$ & $\begin{array}{l}\text { Average } \\
\left(\text { SD }^{*}\right)\end{array}$ & $p$ & $\begin{array}{c}\text { Average } \\
\left(\text { SD }^{\#}\right)\end{array}$ & $p$ & $\begin{array}{c}\text { Average } \\
\left(\text { SD }^{\#)}\right.\end{array}$ & $p$ \\
\hline Female & $9.3(2.8)$ & \multirow{2}{*}{0.873} & $2.1(1.8)$ & \multirow{2}{*}{0.541} & $4.7(1.4)$ & \multirow{2}{*}{0.927} & $4.7(1.4)$ & \multirow{2}{*}{0.927} & $1.6(25)$ & \multirow{2}{*}{0.883} & $3.2(1.9)$ & \multirow{2}{*}{1.000} & $4.5(1.5)$ & \multirow{2}{*}{0.208} \\
\hline Male & $9.1(3.2)$ & & $2.4(1.5)$ & & $4.7(0.7)$ & & $4.7(0.7)$ & & $1.6(2.5)$ & & $3.5(1.2)$ & & $4.0(1.2)$ & \\
\hline \multicolumn{15}{|l|}{$\begin{array}{l}\text { Marital } \\
\text { status }^{\dagger}\end{array}$} \\
\hline With partner & $9.4(2.8)$ & \multirow[b]{2}{*}{0.470} & $2.2(1.9)$ & \multirow[b]{2}{*}{0.786} & $4.7(1.7)$ & \multirow[b]{2}{*}{0.753} & $4.7(1.3)$ & \multirow[b]{2}{*}{0.753} & $1.5(2.5)$ & \multirow[b]{2}{*}{0.326} & $3.2(1.7)$ & \multirow[b]{2}{*}{0.673} & $4.4(1.6)$ & \multirow[b]{2}{*}{0.838} \\
\hline $\begin{array}{l}\text { Without } \\
\text { partner }\end{array}$ & $8.9(3.0)$ & & $1.9(1.8)$ & & $4.7(1.4)$ & & $4.7(1.4)$ & & $1.9(2.5)$ & & $3.4(2.0)$ & & $4.3(1.3)$ & \\
\hline \multicolumn{15}{|l|}{ Ocupation $^{\dagger}$} \\
\hline $\begin{array}{c}\text { Active in the } \\
\text { market }\end{array}$ & $10.1(2.8)$ & \multirow{2}{*}{0.176} & $2.2(2.2)$ & \multirow{2}{*}{0.963} & $5.0(1.0)$ & \multirow{2}{*}{0.481} & $5.0(1.0)$ & \multirow{2}{*}{0.481} & $0.7(0.9)$ & \multirow{2}{*}{0.624} & $2.7(1.5)$ & \multirow{2}{*}{0.195} & $5.0(0.8)$ & \multirow{2}{*}{0.208} \\
\hline $\begin{array}{l}\text { Inactive in the } \\
\text { market }\end{array}$ & $8.9(2.8)$ & & $2.1(1.6)$ & & $4.6(1.3)$ & & $4.6(1.3)$ & & $1.9(2.8)$ & & $3.5(1.9)$ & & $4.2(1.6)$ & \\
\hline \multicolumn{15}{|l|}{$\begin{array}{c}\text { Drug } \\
\text { treatment }\end{array}$} \\
\hline With insulin & $12.0(2.3)$ & \multirow[b]{2}{*}{$0.018^{*}$} & $1.7(1.7)$ & \multirow[b]{2}{*}{0.577} & $4.9(1.5)$ & \multirow[b]{2}{*}{0.773} & $4.9(1.5)$ & & $4.1(2.6)$ & & $2.2(2.9)$ & & $5.9(1.1)$ & \\
\hline $\begin{array}{l}\text { Without } \\
\text { insulin }\end{array}$ & $8.7(2.7)$ & & $2.2(1.8)$ & & $4.7(1.3)$ & & $4.7(1.3)$ & 0.773 & $1.2(2.2)$ & $0.003 *$ & $3.5(1.5)$ & 0.339 & $4.1(1.4)$ & $0.002 *$ \\
\hline
\end{tabular}

†Mann-Whitney test

\#SD: standard deviation

*Statistical significance $(\mathrm{p}<0.05)$

Source: survey data, 2018

Recent Brazilian studies of self-reported prevalence of DM show that the proportion of women affected by the disease is higher than that of men $[18,19]$ and this finding is possibly due to both the longevity of the female population, which favors the development of diseases chronic diseases [20], as well as their greater demand and/or use of health services [21]. Research on surveillance of risk and protective factors for chronic diseases by telephone survey (Vigitel) [19] shows that in both sexes, the frequency of DM increased sharply with age and decreased with increasing schooling, which reiterates the findings of the present study.

The absence of previous participation in groups or activities to guide the disease is similar to the findings of other investigations $[13,17]$. This suggests a devaluation of people in relation to this type of activity, and even a difficulty in assuming their own treatment, as well as the lack of encouragement or appreciation on the part of health services. Both situations can be a barrier to behavioral change [9].

Regarding knowledge about DM, the average score obtained (above eight points) indicates satisfactory knowledge [10], corroborating other Brazilian studies that used the same instrument $[4,11,22]$. This result was not expected due to the fact that no one had previously participated in DM education groups, due to old age and low education, and also because the time of diagnosis is relatively short. A systematic review of educational practices for diabetic patients and health professionals showed that old age did not represent learning difficulties [8] and the little experience with the disease may have been the motivational factor for the search for knowledge, in order to engage in behaviors appropriate to their control, although no correlations were found in the present study between knowledge, age and time of diagnosis. It should also be considered that the advancement of technology has enabled access to resources and sources of information such as the Internet, favoring the acquisition of knowledge about the disease.

On the other hand, direct correlations between knowledge and schooling and monthly family income were observed, suggesting that the higher the education and income, the greater the knowledge about the disease. Cross-sectional study that aimed to assess knowledge using the same instrument, as well as the attitudes and associated factors of 353 users with DM2, accompanied by Primary Health Care in Montes Claros, Minas Gerais, Brazil, also identified a correlation between knowledge and education ( $\mathrm{p}=0.002)$ [13]. Another study, of a quasiexperimental design involving 55 people with DM2, in which one of the objectives was to evaluate functional health literacy (FHL) in the health numbering domain, found that low education may have influenced the low performance of the achieved FHL by the participants [23]. 
These findings are interesting because although there was a direct and statistically significant correlation between education and knowledge about the disease, the sample studied has low education and satisfactory knowledge about DM. It is possible that other factors, such as motivation, coping and acceptance of the disease, which were not investigated in the present study, influenced these findings.

Unlike the present investigation, other studies that used the same knowledge assessment instrument, did not identify correlations between the latter variable and the income of people with DM $[13,24]$. In the analysis of knowledge regarding drug treatment, greater knowledge was observed among insulin users. This finding is probably due to the fact that, due to its complexity, insulin treatment demands greater search for information, even for the prevention and/or correction of eventual episodes of hypoglycemia, resulting from this therapeutic modality [2].

As for self-care activities, the ones that showed the best performance were "specific food" and "physical activity". For the first dimension, the findings are similar to those of other studies that also used the DSCAQ instrument [15-17,25], and differ from those same studies with regard to the second dimension. When analyzing the items that make up the dimension "specific food", it was observed that the highest average was "How many of the last seven days did you eat five or more servings of fruits and / or vegetables?", whose average was $5.4 \pm 2.1$ days / week, which indicates an adequate consumption of these foods; and the lowest average item, $2.3 \pm 2.6$ days / week, was "How many of the last seven days did you eat sweets?" (data not shown). The low consumption of sweets is a positive fact and suggests that these people are aware of the need to restrict sugary foods and drinks. Although correlations between "specific diet" and knowledge have not been shown (data not shown), it is possible that satisfactory knowledge about the disease has contributed to these results.

Good adherence to the "physical activity" dimension, diverging from the literature $[15-17,22,25,26]$, was expected by the fact that $58 \%$ of the sample stated that they practiced some type of physical activity, even if sporadically. Thus, it is assumed that the studied group has more motivation for this aspect of care with DM and that may be the reason why the group accepted to participate in the interventions proposed by the matrix project, which would include concurrent physical training sessions.

The dimensions with the worst performance were "general food", diverging from other studies [15-17,22,25,26] and "blood glucose monitoring", for which there were similarities $[15-17,26]$ and divergences $[22,25]$ between studies.

"General food" showed a direct and statistically significant correlation with monthly family income, unlike other studies [22,25]. It is known that, for people with DM in general, routinely following a healthy diet is a great challenge, whether due to the often unhealthy eating habits, consolidated throughout life, or for cultural and financial reasons. A study that aimed to identify the necessary cost for obtaining a healthy diet in Brazil and to analyze the compromise of this practice in family income, found that reaching the recommendations would increase spending on food by $58 \%$ for individuals with a per capita income of $\leq$ USD \$ 1.00 per capita / day, and 39\% for individuals with an income $\leq \mathrm{R} \$ 415.00$ (Reais), compromising family income by up to $145 \%$ [27]. Another study, which investigated the eating habits of low-income Brazilian families, found that the most important attribute for choosing foods is price and, in the background, its importance for health [28]. More recently, a study that aimed to measure the magnitude of social inequalities in the profile of the Brazilian population's food quality, showed that the best profile of food consumption was identified in the social groups with higher income, higher education and health insurance [29].

It should be noted that this dimension of self-care includes an item related to dietary guidance provided by a health professional. However, most primary care services in small towns in the countryside of Brazil do not have nutritionists, nor nurses who perform nursing consultations for a systematic approach to food. Thus, access to professional guidance may be restricted to people with a higher family income, who may pay for a health plan or even private consultations.

The low performance of the "blood glucose monitoring" dimension can be attributed both to the difficulty of free access to the necessary supplies, since most of the interviewees used OADs, as well as to the difficulties inherent to the procedure itself. An integrative review study on self-monitoring of capillary blood glucose at home revealed that due to socioeconomic (cost of tapes and/or lancets) or psychological (fear of needles, pain from digital puncture or inability to handle the glucometer), many patients do not perform this test procedure [30].

"Blood glucose monitoring" was more frequent among people with longer diagnosis time, as well as among insulin users, corroborating one of the studies previously cited [25]. A longer period of evolution and experience with the disease may allow the development of technical and manual skills, necessary for the blood glucose monitoring procedure, which possibly explains the direct correlation between this last variable and the time of diagnosis. In addition, the increased frequency of monitoring among insulin users denotes the concern or fear of episodes of hypoglycemia, as these are the main acute complication of insulin treatment [2], causing people to try harder to perform this activity.

Finally, the dimension "medication", which performed below satisfactory (less than 5 days/ week) [22], a result that is contrary to those of other studies [22,25,26], also significantly correlated with insulin treatment. This last finding was not expected and differs from the literature, which indicates that adherence to insulin therapy tends to be lower than that of OADs, due to the very technical complexity of this therapeutic modality, as well as to its possibility of weight gain and risk of hypoglycemia [2].

Another aspect to be considered is that the sample consisted mostly of elderly people with low education, conditions commonly seen as barriers to adherence to insulin therapy. However, these conditions do not seem to apply to the studied group. It is believed that this result can be attributed to factors such as motivation, acceptance of the disease, availability of social support networks, and even the perception of better glycemic control, arising from adherence to insulin therapy.

Some limitations of the present study deserve to be pointed out, such as the cross-sectional design and the small sample size, which limit the establishment of evidence about the relationships between the variables of interest. It is recommended that future investigations be carried out on larger samples to explore these variables and possible intervening factors, and their relationship with DM knowledge and self-care activities.

\section{Conclusion}

The sample presented a sociodemographic and clinical profile similar to that of other Brazilian population samples that have the disease. Knowledge about DM was satisfactory, and the self-care activities with the best performance were those related to food and physical activity. The results suggest the existence of relationships between some sociodemographic, clinical and treatment characteristics 
with knowledge and with at least three dimensions of self-care, which should be considered when planning and conducting educational programs for people with DM.

As self-care behaviors are not stable, health professionals must act as supporters, in order to motivate and enable people to develop and improve their self-care skills. Therefore, the identification of variables that can interfere in this process is of fundamental importance to enable greater success in educational actions in controlling the disease and promoting quality of life.

\section{References}

1. Teston EF, Peternella FMN, Sales CA, Haddad MCL, Cubas MR (2018) Effect of the consultation of nursing on knowledge, quality of life, attitude towards disease and selfcare among persons with diabetes. Rev Min Enferm 22: e-1106.

2. Sociedade Brasileira de Diabetes (2017) Diretrizes da Sociedade Brasileira de Diabetes 2017-2018. São Paulo: Clannad.

3. Powers MA, Bardsley J, Cypress M, Duker P, Funnell MM, et al. (2016) Diabetes self-management education and support in type 2 diabetes. Clin Diabetes 34: 70-80. [Crossref]

4. Gonçalves NEXM, Zanetti ML, Neiva CM, Vassimon HS (2017) Knowledge of individuals with diabetes mellitus in the family health strategy. Rev enferm UFPE on line 11: 2779-2787.

5. Galvão MTRLS, Janeiro JMSV (2013) Self-care in nursing: self-management, selfmonitoring, and the management of symptoms as related concepts. Rev Min Enferm 17: $225-230$.

6. American Association of Diabetes Educators (2008) AADE7TM Self-Care behaviors. Diabetes Educ 34: 445-449.

7. Strömberg A (2005) The crucial role of patient education in heart failure. Eur J Heart Fail 7: 363-369.

8. Iquize RCC, Theodoro FCET, Carvalho KA, Oliveira MA, Barros JF (2017) Educational practices in diabetic patient and perspective of health professional: a systematic review. J Bras Nefrol 39: 196-204.

9. Silva Júnior AJ, Gomes LC (2019) Effects of an educational program focused on selfcare and concurrent physical training on glycemia and drug treatment of patients with diabetes mellitus. Diabetes Updates. 2: 1-7.

10. Torres HC, Hortale VA, Schall VT (2005) Validation of Diabetes Mellitus knowledge (DKN-A) and attitude (ATT-19) questionnaires. Rev Saúde Pública 39: 906-911.

11. Figueira ALG, Gomes-Villas Boas LC, Coelho ACM, Foss-Freitas MC, Pace AE (201) Educational interventions for knowledge on the disease, treatment adherence and control of diabetes mellitus. Rev Latino-Am Enfermagem 25: e2863.

12. Michels MJ, Coral MHC, Sakae TM, Damas TB, Furnaletto LM (2010) Questionnaire of Diabetes Self-Care Activities: translation, cross-cultural adaptation and evaluation of psychometric properties. Arq Bras Endocrinol Metab 54: 644-651.

13. Assunção SC, Fonseca AP, Silveira MF, Caldeira AP, Pinho L (2017) Knowledge and attitude of patients with diabetes mellitus in Primary Health Care. Esc Anna Nery 21 e20170208. [Crossref]
14. Cortez DN, Santos JC, Macedo, MML, Souza DAS, et al. (2018) Effects of an educational program on self-care empowerment for the fulfillment of goals in diabetes. Cienc enferm 24: 23-32.

15. Santos EMS, Souza VP, Correio IAG, Correio EBS (2018) The self-care of users bearing diabetes mellitus: socio-demographic, clinical and therapeutic profiles. Rev Fund Care Online 10: 720-728.

16. Marques MB, Coutinho JFV, Martins MC, Lopes MVO, Maia JC, et al. (2019) Educational intervention to promote self-care in older adults with diabetes mellitus. Rev Esc Enferm USP 53: e03517.

17. Oh1 RIB, Chavaglia SRR, Gomes JLGC, Freitas MAO, Gamba MA(2019) Conversation Map as a teaching strategy for the development of self-care in diabetes mellitus. Enferm Foco 10: 110-117.

18. Flor LS, Campos MR (2017) The prevalence of diabetes mellitus and its associated factors in the Brazilian adult population: evidence from a population-based survey. Rev bras epidemiol 20: 16-29. [Crossref]

19. Brazil (2019) Ministério da Saúde. Vigitel Brazil 2018: vigilância de fatores de risco e proteção para doenças crônicas por inquérito telefônico: estimativas sobre frequência e distribuição sociodemográfica de fatores de risco e proteção para doenças crônicas nas capitais dos 26 estados brasileiros e no Distrito Federal em 2018. Brasília: Ministério da Saúde.

20. Pimenta FB, Pinho L, Silveira MF, Botelho ACC (2015) Factors associated with chronic diseases among the elderly receiving treatment under the Family Health Strategy. Ciênc Saúde coletiva 20: 2489-2498.

21. Botton A, Cúnico SD, Strey MN (2017) Gender differences in the access to health services: necesssary problematization. Mudanças - Psicologia da Saúde 25: 67-72.

22. Batista JMF, Teixeira CRS, Becker TAC, Zanetti ML, Istilli PT (2017) Self-care knowledge and activities of people with diabetes mellitus submitted to telephone Support. Rev Eletr Enf 19: a36.

23. Moura NS, Lopes BB, Teixeira JJD, Oriá MOB, Vieira NFC, et al. (2019) Literacy in health and self-care in people with type 2 diabetes mellitus. Rev Bras Enferm 72: 734-740.

24. Teston EF, Serafim D, Cubas MR, Haddad MCL, Marcon SS (2017) Factors associated with knowledge and attitude of diabetic individuals towards diabetes mellitus. Cogitare Enferm 22: e50850.

25. Coelho ACM, Gomes-Villas Boas LC, Gomides DS, Foss-Freitas MC, Pace AE (2015) Self-care activities and their relationship to metabolic and clinical control of people with diabetes mellitus. Texto Contexto Enferm 24: 697-705.

26. Souza JD, Baptista MHB, Gomides DS, Pace AE (2017) Adherence to diabetes mellitus care at three levels of health care. Esc Anna Nery 21: e20170045.

27. Borges CA, Claro RM, Martins APB, Villar BS (2015) The cost of meeting dietary guidelines for low-income Brazilian families. Cad. Saúde Pública 31: 137-148.

28. Defante LR, Nascimento LDO, Lima-Filho DO (2015) Food consumption behavior of low-income households from families of small brazilians cities: the case of Mato Grosso do Sul. Interações 16: 265-276.

29. Medina LPB, Barros MBA, Sousa NFS, Bastos TF, Lima MG (2013) Social inequalities in the food consumption profile of the Brazilian population: National Health Survey, 2013. Rev bras epidemiol 22: E190011.

30. Teixeira CRS, Zanetti ML, Landim CAP, Becker TAC, Santos ECB (2009) Selfmonitoring blood glucose at home: integrative literature review. Rev Eletr Enf 11: 1006-1017.

Copyright: (C2020 Moraes NM. This is an open-access article distributed under the terms of the Creative Commons Attribution License, which permits unrestricted use, distribution, and reproduction in any medium, provided the original author and source are credited. 